\title{
ASPECTOS DA NÃO ANULABILIDADE DO AVAL PRESTADO SEM OUTORGA NA UNIÃO ESTÁVEL
}

\section{ASPECTS OF NO ENDORSEMENT OF ANNULMENT PROVIDED WITHOUT GRANTING THE UNION STABLE}

\author{
${ }^{1}$ Juliana Franco Fulgencio Fonseca
}

\section{RESUMO}

Dada a importância do aval nas atividades econômicas empresariais, o presente estudo tem por escopo a análise da mudança trazida pelo Código Civil de 2002, que ocasionou expressa exigência de autorização do cônjuge para validar aval prestado pelo outro, excetuando-se os casos de regime de separação total de bens. A inovação acarretou uma discussão doutrinária intensa, tendo em vista que a norma trouxe relevantes alterações ao instituto garantidor e que tal imposição não era prevista no Código Civil de 1916. Faz-se uma análise crítica ao art. 1647, III do Código Civil diante do contexto da teoria geral dos títulos de crédito e seus princípios, que clamam pelo dinamismo e pela simplicidade da circulação do crédito. Esclarecem-se as consequências do aval prestado sem outorga no âmbito do casamento e da união estável, bem como a aplicabilidade ou inaplicabilidade dessa imposição face aos títulos de crédito. $\mathrm{O}$ estudo embasa que, além de ser desnecessária a outorga no aval prestado pelo convivente em união estável, mesmo que esta fosse necessária, não ocorreria invalidade do aval (como estipulado pelo Código Civil de 2002), mas sim a ineficácia, não produzindo efeitos perante aquele que não participou do ato.

Palavras-chave: Aval. garantia, Títulos de crédito, Outorga conjugal, Invalidade, Ineficácia

\begin{abstract}
Given the importance of the endorsement in corporate economic activities, the study has the scope to analysis of change brought about by the Civil Code of 2002, which caused expressed spousal authorization requirement to validate guarantee provided by the other, except for cases of separation regime total assets. Innovation led an intense doctrinal discussion, given that the norm has brought significant changes to the guarantor and institute such a levy was not provided for in the Civil Code of 1916. It is a critical analysis of art. 1647, III of the Civil Code on the context of the general theory of debt securities and its principles, calling for the dynamism and simplicity of credit flowing. Clarify to the approval of the consequences provided without granting the marriage scope and stable, as well as the applicability or inapplicability of such a charge against the securities. The study underpins that, besides being unnecessary to grant the guarantee provided by the cohabitant in a stable relationship, even if it were necessary, would not occur invalidity of endorsement (as stipulated by the Civil Code of 2002), but the ineffectiveness have no effect before one who did not attend the act.
\end{abstract}

Keywords: Aval, Warranty, Credit titles, Marriage grant, Invalidity, Ineffectiveness

\footnotetext{
${ }^{1}$ Mestra em Direito pela Faculdades Milton Campos - FMC, Minas Gerais, MG, (Brasil). Professora na Faculdade Milton Campos, FMC, Minas Gerais. E-mail: juliana_fulgencio@ hotmail.com. 


\title{
1 INTRODUÇÃO
}

Face aos anseios evolutivos e às relações humanas e mercantis, foi necessário que o Direito criasse um meio inteligente e prático que fomentasse a economia sem comprometer a segurança financeira dos mercados.

Nesse contexto, os títulos de crédito, no ordenamento jurídico brasileiro, assumiram função de destaque como instrumentos eficientes na captação de recursos. Esses títulos possibilitam a circulação de direitos por meio de instrumentos que visam garantir a segurança da operação, gerando a confiança de que o devedor honrará o crédito colocado à sua disposição.

É indiscutível a ideia de que a economia e o comércio seriam incompreensíveis sem a existência dos títulos de crédito. Nesse sentido, o instituto possibilitou o rompimento dos limites de tempo e de espaço, a fim de transportar, com maior possibilidade, o presente para as riquezas futuras. Além disso, a criação dos títulos de crédito trouxe novos contornos às práticas comerciais, valorizando o crédito, e, conforme Jean Carlos Fernandes (2012, p. 1), "dando-lhe posição de realce no fomento das atividades desenvolvidas pelos outrora comerciantes e agora os modernos empresários”.

Nesse sentido, Tullio Ascarelli (1969, p. 3) pondera:

\begin{abstract}
A vida econômica moderna seria incompreensível sem a densa rêde de títulos de crédito; às invenções técnicas teriam faltado meios jurídicos para a sua adequada realização social; as relações comerciais tomariam necessariamente outro aspecto. Graças aos títulos de crédito pôde o mundo moderno mobilizar as próprias riquezas; graças a êles o direito consegue vencer tempo e espaço, transportando, com a maior facilidade, representados nestes títulos, bem distantes e materializando, no presente, as possíveis riquezas futuras.
\end{abstract}

A segurança necessária para a utilização de tais instrumentos decorre, sobretudo, da autonomia das obrigações cambiais, da literalidade dos títulos e da cartularidade. Com base nos títulos e nas informações dispostas em tais instrumentos, o credor sabe exatamente que crédito é exigível. E, por serem fontes de direito autônomo, distintos da relação que deu origem ao documento, o crédito poderá ser exigido independentemente da relação subjacente.

Como maneira de reforçar o cumprimento das obrigações constantes nos títulos de crédito, surge a figura do aval como garantia cambiária prestada por simples assinatura no anverso da cártula, através da qual o avalista se obriga pelo pagamento do crédito constante no documento, da mesma forma que a pessoa avalizada. 
Diante da importância que temática aqui abordada tem na sociedade contemporânea, o artigo desenvolvido tem por objeto específico a análise do instituto do aval, mormente sobre a mudança trazida a lume pelo novo Código Civil Brasileiro (que introduziu a necessidade de outorga conjugal), tangenciando com os princípios dos títulos de crédito, analisando o conteúdo da Lei Uniforme de Genebra e fazendo uma abordagem de sua inexigibilidade em casos de união estável, sobretudo, à luz do plano da eficácia.

Examina-se a questão da outorga no aval face à união estável, fazendo uma análise comparativa legal desse instituto com o casamento. Nesse último aspecto, defende-se desnecessidade da outorga no aval prestado pelo convivente em união estável diante da análise do fato jurídico à luz do plano da eficácia.

\title{
2 OUTORGA CONJUGAL NO AVAL NA UNIÃO ESTÁVEL
}

\subsection{Aspectos gerais}

O Código Civil não traz o conceito de união estável. E nem deveria. Esse é um dos grandes desafios do direito de família na atualidade, visto que, definir união estável começa e termina por entender o que é família. Não é tarefa fácil conceituar um tema que está sujeito a tantas transformações sociais e culturais, que deixou de ser núcleo econômico e de reprodução para ser espaço de afeto e de amor. Podemos dizer que a união estável é a relação existente entre um homem e uma mulher (ou entre pessoas do mesmo sexo, como já foi reconhecido) duradoura, pública e contínua, que possui a principal finalidade de construção de uma família, como se fossem casados.

De acordo com Paulo Lôbo (2011, p. 168),

\begin{abstract}
A união estável é a entidade familiar constituída por homem e mulher que convivem em posse do estado de casado, ou com aparência de casamento (more uxório). É um estado de fato que se converteu em relação jurídica em virtude de a Constituição e a lei atribuírem-lhe dignidade de entidade familiar própria, com seus elencos de direitos e deveres.
\end{abstract}

Maria Berenice Dias (2013, p. 176) determina:

Nasce a união estável da convivência, simples fato jurídico que evoluiu para a constituição de ato jurídico, em face dos direitos que brotam dessa relação. Paulo Lôbo diz ser a união estável um ato-fato jurídico, por não necessitar de qualquer manifestação ou declaração de vontade para que produza seus jurídicos efeitos. 
Basta sua configuração fática, para que haja incidência das normas constitucionais e legais cogentes e supletivas e a relação fática se converta em relação jurídica.

Para a sua configuração é exigida a efetiva convivência more uxorio, com características de união familiar, por um prazo que denote estabilidade e objetivo de manter a vida em comum entre o homem e a mulher assim compromissado por mais que a união estável seja o espaço do não instituído, à medida em que é regulamentada ganha contorno de casamento. Tudo o que está disposto sobre as uniões extramatrimoniais tem como referencia a união matrimonializada.

A Constituição Federal de 1988 possui normas que objetivam garantir às pessoas que convivem em união estável mesma proteção jurídica conferida às pessoas casadas. $\mathrm{O}$ fato de mencionar primeiro o casamento, depois a união estável e por último a família monoparental não significa uma preferência de tratamentos. Ainda que a união estável não se confunda com o casamento, as duas entidades são equiparadas, detendo mesma proteção. Nesse sentido, Paulo Lôbo sustenta que o caput do art. 226 da CF/88 é cláusula geral de inclusão, não sendo admissível excluir qualquer entidade que preencha os requisitos de afetividade, estabilidade e ostensibilidade.

No âmbito das legislações infraconstitucionais, a lei n. 8.971/1994 assegurou direito aos alimentos e à sucessão do companheiro. Contudo, reconheceu a possibilidade de união estável o relacionamento entre solteiros, pessoas judicialmente separadas, divorciadas e viúvas, deixando de fora, imotivadamente, os separados de fato. Também só reconheceu como estável a relação com mais de cinco anos ou que daquela houvesse nascido prole.

Já a lei 9.278/1996 teve maior abrangência. Não estipulou prazo de convivência para reconhecimento de união estável e incluiu a possibilidade de constituição por pessoas separadas de fato. Fixou a competência para julgamento dos litígios para as varas de família e reconheceu o direito real de habitação. Também criou a presunção júris et de jure, na qual os bens adquiridos onerosamente na Constancia da convivência são de esforço comum, não indagando qual a efetiva participação de cada parceiro para a partilha igualitária dos bens.

No Código Civil de 2002, o instituto da união estável está regulado nos art. 1723 a 1727. De acordo com o art. 1725, à união estável (salvo contrato escrito entre os companheiros), aplica-se às relações patrimoniais, no que couber, o regime de comunhão parcial de bens.

Em virtude do regramento legal na comunhão parcial de bens, há alguns questionamentos na doutrina sobre a exigência de outorga conjugal aos companheiros em união estável para o aval. É o que adiante se abordará. 
Diante das naturais diferenças existentes entre união estável e casamento, é de fundamental relevância determinar os limites e possibilidades de tratamento jurídico equivalente e diferenciado entre eles. Contudo, mesmo com divergências entre os institutos, o Código Civil de 2002 adotou a sistemática protetiva da união entre homem e mulher, (ou entre pessoas do mesmo sexo) que elegem por uma relação de união estável, e ampliou as garantias na seara patrimonial dos companheiros.

Se o tema outorga conjugal no aval já é cercado de debates e controvérsias jurídicas, a definição sobre a exigibilidade, em se tratando de união estável é ainda mais dotada de dúvidas diante das poucas referências doutrinárias e jurisprudenciais acerca do assunto.

\section{.2 Necessidade ou desnecessidade de outorga no aval em caso de união estável}

Diante do contexto da exigência imposta no art. 1647, III do Código Civil, criou-se um debate sobre a necessidade de outorga para que um dos companheiros pudesse avalizar títulos de crédito. Tal divergência se deu pelo fato de que, ao se levar em consideração o disposto no art. 1725 do Código Civil às relações de união estável, aplicar-se-ia o regime da comunhão parcial de bens. E, sabendo que se exige outorga para prestar aval nesse regime, automaticamente, se entenderia pela exigibilidade da autorização conjugal também para os companheiros.

Preliminarmente, a razão da existência do consentimento é conferir validade ao aval prestado e permitir ao companheiro certo controle sobre o patrimônio do casal. Todavia, a questão não é de simples solução, pois parte da doutrina e jurisprudência não entende pela aplicação automática do art. 1725 a esses casos. Isso se deve à expressão "no que couber" contida no artigo em questão.

Apesar de não ser o entendimento adotado nesse estudo, vale apresentar a opinião de doutrinadores que entendem pela aplicação direta do art. 1725 do Código Civil à união estável, corroborando a necessidade de outorga conjugal para conviventes. Para Nelson Rosenval e Cristiano Chaves (2011, p. 439), “a compreensão fundamental da união estável deve, escolhem imperiosamente, emanar da legalidade constitucional, em conformidade com latitudes do comando 226, parágrafo terceiro, da Lex Fundamentallis”. Os mesmos autores ainda acrescentam:

[...] o exame da disciplina jurídica da união estável - assim como de qualquer outra entidade familiar - há de se realizar, necessariamente, à luz do balizamento 
constitucional, dependendo, sempre, do atendimento ao seu elemento finalístico. Nessa ordem de ideias, toda e qualquer norma infraconstitucional, codificada ou não, deverá garantir a especial proteção aos componentes da união estável, sem discriminações, mas também sem privilégios, sob pena de incompatibilidade com a norma constitucional e consequente invalidade.

Por outro lado, Pessoa também possui entendimento contrário ao exposto:

Em função da elevação da união estável à categoria de entidade familiar, nos moldes do art. 226, parágrafo terceiro, da Constituição da República, têm surgido considerações doutrinárias acerca da eventual necessidade de outorga uxória e marital quanto aos atos jurídicos dispositivos praticados por aqueles que vivem em concubinato.

Há que se ter presente que a equiparação efetivada pelo legislador constitucional não teve o condão de elevar o concubinato ao casamento, não tendo havido a transposição pura e simples, para as uniões estáveis, dos mesmos direitos e deveres decorrentes da sociedade conjugal.

A outorga uxória e marital, nesse sentido, são restrições que decorrem diretamente do elenco de direitos e deveres a que estão submetidos os cônjuges, independentemente do regime de bens, e que concernem, precipuamente, à proibição quanto a atos de disposição direta ou indireta de bens do casal, podendo levar à anulação do ato jurídico, quando ausentes.

Diversa é a situação dos concubinos.

A doutrina tem-se manifestado, de maneiro uniforme, quanto à inexistência do dever de obtenção da outorga uxória ou marital em relação aos negócios realizados por qualquer uma das partes que vivam em concubinato.

Considerando que a necessidade de outorga uxória ou marital reflete restrição ao livre arbítrio das partes, não há como aplicar, por analogia, normas de caráter restritivo, inclusive, com sanções nulificantes, independentemente de expressa previsão legal.

Além disso, há de se considerar que, sendo o casamento revestido de formalidades, muitas pessoas preferem a adoção de um relacionamento em união estável para não se submetes às exigências do casamento, que possui legislação rígida, implicando em direitos e deveres que, muitas das vezes, os companheiros sequer querem se submeter. Mesmo que eventual necessidade de outorga conjugal para aval (na união estável) vise à proteção do patrimônio dos companheiros, é importante entender o real objetivo dessa união, que, a nosso ver, não é a rigidez das normas do casamento.

Nesse viés, Vanessa Benincasa (2004, p. 19), em sua dissertação, apresentou o seguinte entendimento:

Não se pode ignorar que aquele que se associa em união estável, muitas vezes o faz precisamente por não desejar submeter-se ao regramento jurídico rígido que é próprio ao casamento e, nessas circunstâncias, não se afigura razoável a aplicação de normas que, em total invasão da vida privada, impõem a essas pessoas uma série de 
deveres e ônus indesejados, sob o pretexto de conceder-lhes proteção pela via do direito.

Sabe-se que essas relações, como a união estável, proporcionam maior liberdade às pessoas. Assim, após breves esclarecimentos sobre as divergências existentes, o estudo defende a posição de que a outorga só é exigível por expressa previsão legal, o que não ocorre na união estável.

No tocante à outorga no aval (união estável), adotar-se-á o entendimento consolidado no STJ, no âmbito da decisão que entendeu pela dispensa de outorga uxória do outro companheiro na fiança.

A decisão defende que as diferenças entre casamento e união estável devem ser analisadas perante a dupla concepção do casamento que, de um lado, é ato jurídico solene (do qual decorre um relação jurídica com efeitos tipificados) e, de outro lado, é entidade familiar, protegida como outras pela Constituição Federal. Sob a perspectiva de ser uma entidade familiar, o casamento em nada se diferencia da união estável, tendo em vista que a Constituição Federal não impõe preferência entre tais entidades.

A distinção está quando se analisa o aspecto do casamento como ato jurídico formal e solene. E, exatamente nesse ponto, em que transita a exigência de outorga uxória a determinados negócios jurídicos, que é justificável a distinção entre união estável e casamento. Já se discutiu, alhures, sobre a necessidade de outorga conjugal no aval, e, através de uma análise, sobretudo, principiológica, entendemos que, no que tange o aval, essa exigência viola certas concepções do direito cambiário e características dos títulos de crédito.

Se no casamento, que é um instituto que, em relação à união estável, detém mais formalidades, defendemos a teoria a desnecessidade do aval e a prática que, aval prestado sem outorga conjugal tem, no muito, ineficácia parcial (não produzindo efeitos ao cônjuge que não participou do ato), na união estável defenderemos a totalidade de sua dispensa.

O casamento é revestido de formalidades tanto para sua celebração quanto para a sua comprovação, o que permite a verificação do estado civil das pessoas vinculadas, ou que pretendem se vincular a determinado negócio jurídico. Já a união estável não concede a mesma segurança.

Sendo conviventes em união estável, hão de ser dispensadas as vênias conjugais para a concessão de fiança e aval, não sendo as referidas garantias nulas ou anuláveis se prestadas sem outorgas do outro companheiro, não incidindo o disposto na súmula 332 do STJ. A 
essência da união estável, entidade familiar, está no sentido de afastar as solenidades e formalidades impostas ao casamento.

Além disso, a lei estabelece a necessidade de outorga entre os cônjuges para prática de atos que possam comprometer o patrimônio comum (art. 1647). Na união estável, nada é referido. Em face dessa omissão, não se poderia exigir consentimento do companheiro na concessão de aval e fiança.

Quanto à proteção do interesse daquele cuja outorga poderia (não é) ser exigível, inicialmente, deve-se entender que a união estável é uma opção de fato, que, embora dotada de proteção legal, sempre apresentará um mínimo que for de insegurança. Essa insegurança poderia ser perfeitamente afastada pelo casamento e, tanto o é, que a própria Constituição Federal tratou de estabelecer medidas para que o legislador infraconstitucional facilitasse a conversão da união estável em casamento.

Entende-se que a outorga só é exigível face à expressa disposição legal, o que não ocorre no caso da união estável. Assim, a exigência de outorga do cônjuge não se estende aos companheiros, pois, em primeiro lugar, assim não quis a lei (como o fez, ainda que incorretamente no que se refere ao casamento) e, em segundo lugar, como visto, a concessão de aval em título de crédito é ato cambiário, que, a exemplo dos demais de mesma natureza, é revestido de autonomia.

Assim, não é nulo o aval prestado por convivente em união estável sem a autorização do companheiro (a chamada outorga uxória, exigida no casamento). A esse respeito, já houve entendimento da Quarta Turma do Superior Tribunal de Justiça, ao julgar recurso interposto por uma empresa do Distrito Federal:

EMBARGOS DE DECLARAÇÃO. FIANÇA. FIADORA QUE CONVIVIA EM UNIÃO ESTÁVEL. INEXISTÊNCIA DE OUTORGA UXÓRIA. DISPENSA. VALIDADE DA GARANTIA. INAPLICABILIDADE DA SÚMULA N. 332/STJ. MATÉRIA EXAUSTIVAMENTE ANALISADA. IMPROPRIEDADE DA VIA ELEITA.

1. Descabe, em sede de embargos de declaração, a rediscussão de matéria meritória exaustivamente analisada pelo acórdão embargado.

2. Embargos de declaração rejeitados.

ACÓRDÃO

Vistos, relatados e discutidos os autos em que são partes as acima indicadas, acordam os Ministros da QUARTA Turma do Superior Tribunal de Justiça, por unanimidade, rejeitar os embargos de declaração, nos termos do voto do Sr. Ministro Relator. Os Srs. Ministros Raul Araújo (Presidente), Maria Isabel Gallotti, Antonio Carlos Ferreira e Marco Buzzi votaram com o Sr. Ministro Relator. Brasília, 22 de abril de 2014 (data do julgamento). MINISTRO LUIS FELIPE SALOMÃO Relator. 


\section{RELATÓRIO \\ O SENHOR MINISTRO LUIS FELIPE SALOMÃO (Relator): \\ 1. São embargos de declaração opostos contra acórdão assim ementado: DIREITO CIVIL-CONSTITUCIONAL. DIREITO DE FAMÍLIA. CONTRATO DE LOCAÇÃO. FIANÇA. FIADORA QUE CONVIVIA EM UNIÃO ESTÁVEL. 2. INEXISTÊNCIA DE OUTORGA UXÓRIA. DISPENSA. VALIDADE DA GARANTIA. INAPLICABILIDADE DA SÚMULA N. 332/STJ.}

1. Mostra-se de extrema relevância para a construção de uma jurisprudência consistente acerca da disciplina do casamento e da união estável saber, diante das naturais diferenças entre os dois institutos, quais os limites e possibilidades de tratamento jurídico diferenciado entre eles.

2. Toda e qualquer diferença entre casamento e união estável deve ser analisada a partir da dupla concepção do que seja casamento - por um lado, ato jurídico solene do qual decorre uma relação jurídica com efeitos tipificados pelo ordenamento jurídico, e, por outro, uma entidade familiar, dentre várias outras protegidas pela Constituição.

3. Assim, o casamento, tido por entidade familiar, não se difere em nenhum aspecto da união estável - também uma entidade familiar -, porquanto não há famílias timbradas como de "segunda classe" pela Constituição Federal de 1988, diferentemente do que ocorria nos diplomas constitucionais e legais superados. Apenas quando se analisa o casamento como ato jurídico formal e solene é que as diferenças entre este e a união estável se fazem visíveis, e somente em razão dessas diferenças entre casamento - ato jurídico - e união estável é que o tratamento legal ou jurisprudencial diferenciado se justifica.

4. A exigência de outorga uxória a determinados negócios jurídicos transita exatamente por este aspecto em que o tratamento diferenciado entre casamento e união estável é justificável. É por intermédio do ato jurídico cartorário e solene do casamento que se presume a publicidade do estado civil dos contratantes, de modo que, em sendo eles conviventes em união estável, hão de ser dispensadas as vênias conjugais para a concessão de fiança.

5. Desse modo, não é nula nem anulável a fiança prestada por fiador convivente em união estável sem a outorga uxória do outro companheiro. Não incidência da Súmula n. 332/STJ à união estável.

6. Recurso especial provido.

Corroborando a inaplicabilidade do comando contido no art. 1647 às relações

convivenciais, o Tribunal de Justiça de São Paulo assim decidiu:

Ação declaratória de nulidade. Escritura pública de compra e venda. Imóvel. Sentença de improcedência. Negócio jurídico celebrado pelo companheiro sem a anuência da companheira. Possibilidade. Outorga uxória. Desnecessidade. Exigência legal que não se aplica à hipótese de união estável. Negócio efetuado em garantia de empréstimo. Simulação configurada. Elementos de convicção que estão a revelar autêntico pacto comissório. Infração ao art. 765 do Código Civil de 1916 (Art. 1.428 do Código Civil atual). Precedentes desta C. Câmara e do STJ. Anulação do negócio jurídico e cancelamento do respectivo registro imobiliário. Ação procedente. Sucumbência invertida. Recurso provido.

(Processo: CR 3961004600 SP Apelação no 396.100.4/6-00 Relator(a): Ariovaldo Santini Teodoro. Julgamento:15/04/2008 Órgão Julgador: $2^{\mathrm{a}}$ Câmara de Direito Privado Publicação:23/04/2008)

Ação declaratória de nulidade. Escritura pública de compra e venda. Imóvel. Sentença de improcedência. Negócio jurídico celebrado pelo companheiro sem a anuência da companheira. Possibilidade. Outorga uxória. Desnecessidade. Exigência legal que não se aplica à hipótese de união estável. (...) (TJSP, Apelação com 
revisão 396.100.4-6, Acórdão 2567068, Itararé, $2^{\text {a }}$ Câmara de Direito Privado, Rel. Des. Ariovaldo Santini Teodoro, j. 15.04.2008, DJESP 16.05.2008).

Também, nesse sentido, entenderam o TJMG e TJPR:

\begin{abstract}
APELAÇÃO CÍVEL - PEDIDO DE DECLARAÇÃO DE NULIDADE DE ATO JURÍDICO, CONSISTENTE EM VENDA DE IMÓVEL PELA CONVIVENTE, SEM A ANUÊNCIA DO COMPANHEIRO E SOB COAÇÃO DESCABIMENTO UNIÃO ESTÁVEL EQUIPARAÇÃO E NÃO IGUALDADE COM OS EFEITOS DO MATRIMÔNIO - IMPOSSIBILIDADE DE INVALIDAÇÃO DE NEGÓCIO JURÍDICO CELEBRADO PELA CONVIVENTE A QUAL APRESENTA-SE COMO DIVORCIADA E COMO ÚNICA PROPRIETÁRIA DO IMÓVEL DESNECESSIDADE DA OUTORGA UXÓRIA NA UNIÃO ESTÁVEL PREVALÊNCIA DO PRINCÍPIO DA BOA-FÉ DOS ADQUIRENTES, SENDO ACOBERTADAS AS RELAÇÕES JURÍDICAS PELA TEORIA DA APARÊNCIA NÃO COMPROVAÇÃO DE VÍCIO DE CONSENTIMENTO INEXISTÊNCIA DE NULIDADE - LITIGÂNCIA DE MÁ-FÉ OCORRENTE (MAIORIA) AÇÃO JULGADA IMPROCEDENTE -

Não há imposição legal da outorga uxória na união estável, haja vista basear-se as relações com terceiros no principio da boa-fé com que se praticam os atos jurídicos, acobertadas tais relações, pois, pela teoria da aparência. Apelação desprovida. (TAPR. Apelação Cível 118667-2. 2ª Câmara Cível. Rel. Juiz Cristo Pereira).
\end{abstract}

\begin{abstract}
Apelação cível. Ação declaratória de nulidade de ato jurídico. União estável não declarada. Venda de bem imóvel a terceiro de boa-fé. Inexistência de hipóteses de invalidade do negócio jurídico. Inexistências de nulidade. 1 - ainda que seja possível vislumbrar pelas provas carreadas a existência de união estável entre apelante e primeiro apelado, a venda de bem imóvel a terceiro de boa-fé não é nula, tendo em vista que a Lei não exige a outorga uxória da companheira. 2 - não comprovadas nenhuma das hipóteses de invalidade do negócio jurídico, previstas nos arts. 166 e ss., do CC 2002, não há nulidades a serem declaradas (TJMG, Apelação cível APCV 1.0284.07.006501-6/0011, Guarani, 9ª Câmara Cível, Rel. Des. Pedro Bernardes, j. 17.02.2009, DJEMG 16.03.2009).
\end{abstract}

Dessa maneira, a união estável, com o advento da Constituição Federal de 1988, passou a ter caráter de entidade familiar para efeito da proteção do Estado e para facilitar sua conversão em casamento. Contudo, deve ser visualizada, no entanto, a equiparação, com algumas ressalvas, já que não há uma efetiva igualdade com o instituto do casamento, não produzindo sempre os mesmos efeitos.

Por óbvio, destarte, que a lei equiparou o convivente somente em alguns aspectos, com o escopo de fazer valer determinados efeitos jurídicos, ao cônjuge. Porém, se a lei especial nada observou sobre a necessidade da outorga uxória pela convivente, por certo que o legislador pátrio não quis o efeito jurídico da nulidade do contrato pela ausência dela. Assim, não há imposição legal da outorga uxória para união estável.

É importante observar a relação marital e a união estável, a par de obrigações pessoais, como um encadeamento de relações econômicas (produção de riquezas, aquisição de bens de consumo etc.) as quais não constituem um fim em si mesmas, mas um meio para satisfação de 
objetivos em comum dos conviventes. A exigência de outorga para os negócios de maior expressão econômica, previstos no art. 1647 do Código Civil, como a prestação de aval, decorre da necessidade de garantir aos cônjuges e aos companheiros forma de controle da gestão patrimonial, tendo em vista eventual dissolução do vínculo, cujo acontecimento enseja interesse na partilha dos bens adquiridos na constância da união.

Porém, de outro lado, como mencionado, existe a questão de um dos principais objetivos de quem formaliza em relacionamento por união estável: a liberdade e não rigidez de determinadas normas.

Diante dessa dupla concepção, a análise da necessidade ou não da vênia do companheiro para o aval deve ser precedida de uma ponderação sistemática entre interesses, além dos já abordados: o interesse dos terceiros de boa-fé e do credor (que celebrou o negócio jurídico), bem como o interesse do companheiro, que não era parte do negócio celebrado.

Sobre o credor, quando ocorre a celebração de um negócio jurídico, este desconhece, na maioria das vezes, o tipo de relação familiar que a outra parte possui. Em um primeiro momento, o credor não sabe se aquela pessoa com que está contraindo um negócio jurídico tem uma união estável ou não. No que se refere ao companheiro, deve-se possuir forma de realizar um controle patrimonial, eis que bens adquiridos onerosamente na constância da união estável pertencem a ambos.

Ponderando sobre esses interesses, há de se preservar o interesse do credor e dos terceiros de boa-fé. Esse entendimento é compartilhado por Bruno Vaz de Carvalho (2008, p. 463):

\footnotetext{
A própria essência da União Estável, relação familiar digna de sua preservação em todos os níveis, como forma de realização pessoal, é no sentido de se afastar solenidades e formalidades impostas no casamento, e requisitos inafastáveis em diversos negócios jurídicos, que não poderão conviver dúvidas e incertezas, além daquelas inerentes ao próprio desenvolvimento da relação jurídica.
}

Concordar com a possibilidade de um companheiro pleitear a anulação de um aval sem vênia seria conferir insegurança, ao credor, do recebimento constante no título de crédito. E, sendo o aval um instrumento garantidor do cumprimento da obrigação, sua anulação por pessoa alheia ao título, que tenha união estável com o avalista, geraria uma profunda desconfiança e insegurança em relação ao instituto, por ora já devidamente caracterizado dentro de sua indiscutível função no direito cambiário.

A circulação do crédito estaria sendo dificultada, descaracterizando, praticamente, a essência do aval. O credor não teria segurança de que aquela garantia seria utilizada para o pagamento da obrigação, caso o devedor do título não honrasse com o pagamento no 
vencimento. Sob esse prisma, o melhor entendimento está no sentido de não ser estendida à união estável a exigência de outorga conjugal, sendo o aval prestado sem a imposição de vênia.

Ao mesmo tempo, o companheiro não estaria vulnerável (apesar de ter preferido a formalização de um regime menos rígido), em relação aos interesses patrimoniais, visto que eventual cobrança incidiria apenas sobre o parceiro que celebrou o negócio jurídico, garantido-se, assim, sua meação, caso o aval não tenha sido dado em proveito da família.

Existe outro desdobramento com relação à matéria: quando ocorre o reconhecimento da união estável após o término da relação. Sobre esse assunto, será elaborada uma breve análise, visto que o objetivo principal do estudo não sofre implicações sobre esse desdobramento.

A união estável pode ser reconhecida entre os companheiros após o término da relação, o que, na prática, é extremamente comum. Ao término do relacionamento, as pessoas buscam o reconhecimento da união estável judicialmente, visando os direitos advindos do relacionamento que tiveram. Sobre o assunto, não se trata apenas do avalista informar que possui uma união estável. Muitas das vezes ele sequer sabe que vive uma relação que pode se tornar uma união estável, para que a outorga do companheiro fosse exigida.

Nesse caso, como aceitar a hipótese de um aval prestado, teoricamente por uma pessoa solteira, que se declare assim, ser anulado devido ao reconhecimento judicial a posteriori de uma união estável, no qual, não houve consentimento do companheiro? Por óbvio, o terceiro de boa-fé deve ser resguardado na medida em que está sob posse de um título de crédito que traduz o seu direito autônomo, com toda a segurança que lhe é peculiar. Não seria razoável anular o aval diante da falta de autorização do companheiro, especialmente nessa pressuposição.

O crédito do empresário e do terceiro de boa-fé deve ser sempre privilegiado, pois, como visto, possibilita a circulação de riquezas e fundamenta a economia do país. Desse modo, e necessário o sobesamento de valores e consequências. Além disso, faz-se necessário, também, que se tenha um mínimo de confiança em um relacionamento de união estável e, ao mesmo tempo, que se vise o resguardo ao patrimônio. A anulação de um aval, nessas condições, não tem respaldo algum. É mais importante, nessa circunstância, tutelar o crédito, protegendo o terceiro de boa-fé de eventual anulação da garantia prestada, devido a uma relação alheia ao título. 
Joaquim Inoja (2014, p. 162) apresenta um questionamento que, no contexto da união estável, é perfeitamente aplicável:

\begin{abstract}
Mas, responderão os apologistas do consentimento prévio, é necessário defender o patrimônio do lar, ameaçado com o direito que tem o seu administrador de comprometê-lo com avaes. Esquecem, ou fingem esquecer, que para isso, a seguir tão especioso raciocínio, seria preciso sujeitar-se á outorga toda espécie de garantia. Com essa restrição apenas, não chegariam á meta aconselhada. Realmente, si o marido fica com a liberdade de aceitar ou endossá-las, como evitar que os bens do casal respondam por dividas que tenham contraído, ou que ele, perdulário, comprometa os bens comuns?

Não avalizei, porém, aceita, emite, endossa.
\end{abstract}

Aos companheiros é facultada a prática de diversos atos que poderiam comprometer o patrimônio do casal, e, que mesmo assim, não necessitam de outorga. Qual o motivo para essa exigência no aval? Vanessa Benincasa (2004, p. 98) defende que:

Por fim, não há de se cogitar em outorga entre convivente, por ausência de previsão legal expressa, o que obsta ao exercício da autonomia privada para situações não compreendidas em seu âmbito de incidência. Esse é o caso da união estável, lembrando-se que a previsão do artigo 1725 do Código Civil, acerca da aplicação do regime de comunhão parcial aos conviventes, não pode ser confundida com a imposição de ônus que decorre não do regime patrimonial agora, mas da condição jurídica de casado.

\title{
2.3 CONSEQUÊNCIAS DO AVAL PRESTADO SEM OUTORGA À LUZ DO PLANO DA EFICÁCIA
}

O tema principal do presente estudo é a análise dos efeitos da outorga conjugal para o aval, sobretudo, no instituto da união estável, mediante a abordagem da teoria do fato jurídico, principalmente sob a perspectiva da ineficácia para ponderar as consequências jurídicas geradas. Para chegar-se ao objetivo, analisou-se o aval sob a ótica dos princípios do Direito Cambiário, suas características, consequências e natureza jurídica.

Tecidos os devidos conceitos, em capítulos iniciais, passa-se ao exame das consequências e efeitos do aval prestado sem outorga. Para isso, é importante registrar a atual posição doutrinária e jurisprudencial sobre o assunto no que se refere à fiança. Embora, como debatido, existam diferenças entre aval e fiança, a exigência de outorga conjugal para ambos consta do art. 1647, III do Código Civil. A fiança, ato jurídico sujeito à legislação civil, teve sua validade diretamente relacionada com a outorga conjugal. 
Alguns Tribunais firmaram entendimento no sentido da nulidade da fiança concedida sem anuência conjugal. Como é o caso do acórdão proferido pelo Superior Tribunal de Justiça:

DIREITO CIVIL. PROCESSUAL CIVIL. RECURSO ESPECIAL. LOCAÇÃO. PREQUESTIONAMENTO. AUSÊNCIA. SÚMULAS 282/STF E 211/STJ. DEFICIÊNCIA DE FUNDAMENTAÇÃO. SÚMULA 284/STF. FIANÇA. OUTORGA UXÓRIA. AUSÊNCIA. NULIDADE. PRECEDENTES. RECURSO ESPECIAL CONHECIDO E IMPROVIDO.

[...] 3. É nula a fiança prestada sem a anuência do cônjuge do fiador. (REsp 797.853/SP, Rel. Ministro Arnaldo Esteves Lima, Quinta Turma, julgado em 27/03/2008, DJe 28/04/2008).

Contudo, após uma análise mais profunda das compreensões jurisprudenciais, é possível notar que, atualmente, o STJ tem adotado a orientação da decisão proferida no já citado RESp:1.163.074, bem como da súmula 332: “A fiança prestada sem autorização de um dos cônjuges implica a ineficácia total da garantia."

Sobre o aval, o contexto juridico do país exterioriza uma situação peculiar. Embora a lei disponha que o aval sem a devida outorga é anulável (em casos de casamento), nada foi disposto sobre a união estavel. Assim, o entendimento doutrinário e jurisprudencial se dá no sentido de atribuir ineficácia parcial, não produzindo efeitos perante o companheiro que não participou do ato. Assim, o credor, além de não ser prejudicado, tem a possibilidade de executar os bens do avalista até o limite dos seus bens particulares, no limite da meação que lhe é de direito.

Além de ser desnecessária a outorga no aval prestado pelo convivente em união estável, mesmo que necessária fosse, sua ausência não invalidaria o aval, mas causaria a ineficácia, não gerando efeitos perante àquele que não participou do ato. A garantia do aval incidiria tão somente quanto ao patrimônio do avalista, atraindo a ineficácia da garantia em relação ao convivente que não anuiu a operação. Eis o entendimento do professor Jean Carlos Fernandes (2011, p. 312): “Destarte, o aval prestado sem outorga mantém a sua higidez, em razão dos princípios da cartularidade, autonomia e independência das obrigações. Não se trata, portanto de invalidade do aval em tal caso, mas apenas em sua ineficácia parcial no tocante ao cônjuge dissidente".

Corroborando tal entendimento, o Enunciado 114 da Jornada de Direito Civil apresenta o seguinte: "O aval não pode ser anulado por falta de vênia conjugal, de modo que o inc. III do art. 1.647 apenas caracteriza a inoponibilidade do título ao cônjuge que não assentiu". 
Claramente a ausência de outorga no aval em casos de união estável se encontra no plano da eficácia do ato jurídico. Eventual ausência de outorga não acarretará em invalidade do aval, como proclama o art. 1649 do Código Civil (inaplicável, como defendido aos títulos de crédito regulados em leis especiais). Deve-se ater ao fato de que aval é obrigação cambial, ndependente e autônoma, não se restringindo à condição extracartular para sua validade, como é o caso da outorga, por exemplo.

O aval deve seguir os comandos do direito cambiário, os quais se sobrepõem ao art. 1647, III do Código Civil, o que, inclusive, foi reconhecido pelo art. 903 do mesmo diploma. A ausência de outorga na união estável pode configurar ineficácia parcial do ato, não produzindo efeitos quanto ao companheiro que não prestou a anuência, o qual poderá requerer e defender sua meação no patrimônio comum. Entendimento diverso pode violar os princípios dos títulos de crédito.

\section{CONCLUSÃO}

A dinamicidade e simplicidade existentes na utilização do aval como meio de garantia cambiária foram rompidas pela norma do art. 1647, III do Código Civil. A exigência de outorga conjugal no aval é injustificável: a proteção da tutela da família sobre o crédito é desmedida, pois vai de encontro com todos os princípios que visam garantir a certeza e a circulação dos títulos cambiais. A aplicação da norma deve ser proporcional no sentido de não prejudicar completamente a utilização do aval, instituto próprio do Direito Cambiário.

O art. 903 do Código Civil deve ser interpretado no sentido de que, sempre que a lei especial estabelecer que o aval decorra de simples ato praticado pelo avalista, sem a concorrência de outro requisito ou condição, o Código Civil cederá e não será aplicado na relação cambial. Assim, preservam-se ambos os interesses: da agilidade e da segurança necessárias às relações cambiais e da família, no tocante ao patrimônio, como pretenderam a Constituição Federal de 1988 e o Código Civil de 2002.

No que diz respeito ao aval, objeto do trabalho, o mesmo se materializa com a assinatura simples do garantidor, que pode fazer parte ou não da cadeia cambial. Na medida em que a ausência de outorga não indica a incapacidade, é de se concluir que o art. 1647, III do Código Civil inovou, estabelecendo norma que viola claramente as legislações especiais dos títulos de crédito. Nesse último aspecto, enfocou-se na autonomia em relação à obrigação do avalizado, extraindo as consequências resultantes, em uma área em que grassam profundas divergências na doutrina e na jurisprudência. No Brasil, desde o advento do Decreto 2.044 de 
1908, tem-se enfatizado a autonomia da obrigação do avalista.

No tocante à necessidade de outorga na união estável para a prestação do aval, a jurisprudência, principalmente os tribunais inferiores, tem se direcionado no sentido de que a ausência da outorga no aval não gera sua anulação, mas apenas a sua ineficácia em relação ao companheiro não anuente. Essa interpretação é de suma importância na medida em que, obviamente, a possibilidade de anulação do aval ante a ausência de outorga fere diretamente o rigor que prevalece (ou deveria prevalecer) no Direito Cambial. Assim, a interpretação da ineficácia do aval em relação ao companheiro que não anuiu expressamente é a mais adequada para a tutela do crédito, privilegiando o terceiro de boa-fé e a circulação de riquezas.

O Superior Tribunal de Justiça já tem entendimento pacificado em relação à fiança, e, a partir dessas decisões, entende-se que a interpretação da ineficácia relativa do aval é plenamente cabível, face às abordagens realizadas sobre ambos os institutos garantidores. A outorga, como requisito de validade do aval, acaba por travar a celeridade das negociações, representando certa contradição da normatividade do instituto, afetando a função primordial dos títulos de crédito. Desse modo, buscou-se abordar que a ausência de outorga (no casamento e estendendo a interpretação para a união estável) não é capaz de invalidar o aval, conforme Enunciado 114 do Centro de Estudos Judiciários do Conselho da Justiça Federal, que estipulou: "O aval não pode ser anulado por falta de vênia conjugal, de modo que o inciso III do art. 1647 apenas caracteriza a inoponibilidade do título ao cônjuge que não assentiu".

Assim, diante da ausência de outorga conjugal, a garantia cambiária terá ineficácia parcial, pois o patrimônio/meação do cônjuge ou companheiro que não deu sua vênia, não poderá ser atingido. Deve-se, portanto, buscar um equilíbrio entre o Direito de Família e o Direito Cambiário, para que a aplicação de normas comuns não afete completamente seus pilares. A ausência de outorga, no que tange o aval, está diretamente ligada ao plano da eficácia, e não ao plano da validade. E, a falta de outorga, na união estável, em títulos de crédito, não constitui invalidade, mas ineficácia parcial do ato.

\section{REFERÊNCIAS}

ARNOLDI, Paulo Roberto Colombo; SILVA, Marcos Paulo Félix da. Os títulos de crédito no novo Código Civil. Rio de Janeiro: Revista dos Tribunais, 2004.

ASCARELLI, Tullio. In: ROCHA, Pedro Figueiredo. Outorga conjugal no aval. Belo Horizonte: D’Plácido. 2014. 
ASCARELLI, Tullio. In: STAJN, Rachel; VERÇOSA, Haroldo Malheiros Duclerc. A Disciplina do Aval no Novo Código Civil. Revista de Direito Mercantil, n. 128, ANO.

ASCARELLI, Tullio. Teoria geral dos títulos de crédito. Campinas: Mizuno, 2003.

AZEVEDO, Antônio Junqueira de. Negócio jurídico: existência, validade e eficácia. 4. ed. São Paulo: Saraiva, 2010.

BENINCASA, Vanessa. Regimes Patrimoniais da Família. Dissertação de Mestrado. Faculdade de Direito da Universidade de São Paulo. São Paulo, 2004.

BETTI, Emilio. Teoria geral do negócio jurídico. Tradução de Servanda Editora. Campinas: Servanda Editora, 2008.

BEVILÁQUA, Clóvis. Direito de Família. 9 ed. Rio de Janeiro: Freitas Bastos, 1959.

BORGES, João Eunápio. Do aval. Rio de Janeiro: Forense. 1955a.

BORGES, João Eunápio. Títulos de crédito. 2 ed. Rio de Janeiro: Forense, 1977.

BRASIL. Código Civil. Brasília: Câmara dos Deputados, Centro de Documentação e Informação, 2002.

BRUNNER, Giuseppe Ferri. In: LUCCA, Newton de. Aspectos da Teoria Geral dos Títulos de Crédito. São Paulo: Livraria Pioneira, 1979.

BULGARELLI, Waldírio. Títulos de Crédito. 16 ed. São Paulo: Atlas, 2000.

CAPUTO, Eduardo. Titoli di Credito - Repertorio completo di dottrina e giurisprudenza dal 1937 al 1969. In: ROCHA, Pedro Figueiredo. Outorga conjugal no aval: encontros e desencontros entre legislação e jurisprudência. Belo Horizonte: D’Plácido, 2014.

CARVALHO, Bruno Vaz de. Aval e outorga no casamento e na união estável. In: ALVES, Alexandre Ferreira de Assumpção; GAMA, Guilherme Calmon Nogueira da (Coord.). Temas de direito civil-empresarial. Rio de Janeiro: Renovar, 2008,

CARVALHO, Bruno Vaz de. Aval e outorga no casamento e na união estável. In: CARVALHO, Francisco Pereira de Bulhões. Sistema de nulidades dos atos jurídicos. Rio de Janeiro, 1980.

COELHO, Fabio Ulhoa. Manual de Direito Comercial. 27 ed. São Paulo: Saraiva. 2015.

COSTA, Wille Duarte. Títulos de Crédito. 2 ed. Belo Horizonte: Del Rey, 2006.

COSTA, Wille Duarte. Títulos de crédito. 3 ed. Belo Horizonte: Del Rey, 2007.

DE LUCCA, Newton. Aspectos da Teoria Geral dos Títulos de Crédito. São Paulo: Pioneira, 1979. 
DIAS, Maria Berenice. Manual de Direito das Famílias. 9 ed. São Paulo: Revista dos Tribunais. 2013.

DINIZ, Maria Helena. Curso de Direito Civil. 28 ed. São Paulo: Saraiva, 2013.

DONNINI, Rogério Ferraz. Responsabilidade Civil Pós-Contratual. 2 ed. São Paulo: Saraiva, 2007.

FARIAS, Cristiano Chaves de; ROSENVALD, Nelson. Direito Civil: Teoria Geral. 9 ed. Rio de Janeiro: Lumen Juris, 2011.

FERNANDES, Jean Carlos. Cessão fiduciária de títulos de crédito: a posição do credor fiduciário na recuperação judicial da empresa. Rio de Janeiro: Lúmen Juris. 2009.

FERnANDES, Jean Carlos. Teoria Contemporânea dos Títulos de Crédito. Belo Horizonte: Arraes. 2012a.

FIQUEIREDO, Joaquim Canuto. Outorga uxória: quando exigível? Revista Forense, Belo Horizonte: Imprensa Official do Estado de Minas Gerais, jul/dez de 1910.

FLORES, Paulo Roberto Moglia Thompson. Direito Civil Parte Geral: das pessoas, dos bens e dos fatos jurídicos. Brasília: Gazeta jurídica. 2013.

FRANCESCHINI, José Luiz Vicente de Azevedo. Títulos de Crédito: Títulos e Papéis de Crédito, na Doutrina e na Jurisprudência. v. I, A a C, São Paulo: Revista dos Tribunais, 1967.

GALIZZI, Gustavo Oliva; FÉRES, Marcelo Andrade. O aval e a outorga conjugal instituída pelo código civil de 2002. Jus Navigandi, Teresina, ano 10, n. 858, 8 nov. 2005. Disponível em: <http://jus2.uol.com.br/doutrina/texto.asp?id=7526>. Acesso em: 20 maio 2015.

GOMES, Orlando. Introdução ao Direito Civil. 18 ed. Rio de Janeiro. Forense, 2002.

GONÇALVES NETO, Alfredo de Assis. Aval: Alcance da Responsabilidade do Avalista. São Paulo: Revista dos Tribunais, 1987.

GUIMARÃES, Luís Paulo Cotrim. Negócio Jurídico sem a Outorga do Cônjuge ou Convivente. São Paulo: Revista dos Tribunais, 2003.

HOUAISS, A; VILLAR, M; FRANCO, FM. Dicionário Houaiss da língua portuguesa. Rio de Janeiro: Objetiva, 2001.

INOJOSA, Joaquim. Aval e Fiança. Rio de Janeiro: Freitas Bastos, 1931.

LÔBO, Paulo Luiz Netto. Código Civil Comentado: direito de família, relações de parentesco, direito patrimonial. São Paulo: Atlas, 2003.

MAMEDE, Gladston. Títulos de Crédito. São Paulo: Atlas, 2003.

MARTINS, Fran. Títulos de crédito: letra de câmbio e nota promissória segundo a lei uniforme. 13 ed. v. I. Rio de Janeiro: Forense, 2001. 
MARTINS, Fran. Títulos de Crédito. 14 ed. Rio de Janeiro: Forense. 2008.

MELlO, Marcos Bernardes de. Teoria do Fato Jurídico. Plano da Existência. 20 ed. São Paulo: Saraiva, 2014.

MENDONÇA, José Xavier Carvalho de. Tratado de Direito Comercial Brasileiro. 2 ed. v. 5, livro 3. Rio de Janeiro: Freitas Bastos, 1934.

MIRANDA, Francisco Cavalanti Pontes de. Tratado de Direito Privado: parte especial. t. XXXIV, atualizado por Rachel Sztajn, São Paulo: Revista dos Tribunais, 2012.

MIRANDA, Francisco Cavalcanti Pontes de. In: MELLO, Marcos Bernardes de. Teoria do fato jurídico: Plano da Existência. 19 ed. São Paulo: Saraiva, 2013.

MOREIRA ALVES, José Carlos. Direito Romano. In: TRIGNELLI, Wania do Carmo de Carvalho. Conversão de Negócio Jurídico: doutrina e jurisprudência. Belo Horizonte: Del Rey, 2003.

NERY JUNIOR, Nelson; NERY, Rosa Maria Andrade. Código civil anotado e legislação extravagante. 2 ed. São Paulo: Revista dos Tribunais, 2003.

PAES. P.R. Tavares. O Aval no Direito Vigente: Doutrina, Jurisprudência e Legislação. São Paulo: Revista dos Tribunais, 1982.

PEREIRA, Caio Mário da Silva. Instituições de Direito Civil: volume 1: Introdução ao direito civil, teoria geral de direito civil. 23 ed. revista e atualizada por Maria Celina Bodin de Moraes. Rio de Janeiro: Forense, 2010.

PEREIRA, Rodrigo da Cunha. Da União Estável. In: DIAS, Maria Berenice. Direito de família e o novo Código Civil. 3 ed. Belo Horizonte: Del Rey, 2003.

PERSECHINI, Sílvia Ferreira. Outorga conjugal no aval: uma análise no plano da eficácia do fato jurídico. Belo Horizonte: Del Rey, 2012.

REALE, Miguel. Lições Preliminares de Direito. 27 ed. ajustada ao novo Código Civil. São Paulo: Saraiva, 2006.

RESTIFFE, Paulo Sérgio. Garantias Tradicionais no Novo Código Civil. Revista dos Tribunais, v. 821, São Paulo: Editora Revista dos Tribunais, 2004.

ROCHA, Pedro Figueiredo. Outorga conjugal no aval: encontros e desencontros entre legislação e jurisprudência. Belo Horizonte: D’Plácido, 2014.

ROSA JÚNIOR, Luiz Emygdio Franco da. Títulos de crédito. 3 ed. Rio de Janeiro: Renovar. 2004.

TARTUCE, Flávio. A Questão da Outorga Conjugal: alguns pontos do art. 1647 do Código Civil. Disponível em:< https://www.flaviotartuce.adv.br/artigos/TARTUCE _OUTORGA 
.doc> Acesso em: 30 maio 2015.

THEODORO JÚNIOR, Humberto. Comentários ao novo Código Civil. 4 ed. v. III, t. II. Rio de Janeiro: Forense, 2008.

TORRAES, Antônio Margarino. Nota Promissória, estudos da lei, da doutrina e da jurisprudência cambial brasileira. Brasília: História do Direito Brasileiro, 2003.

TRIBUBAL DE JUSTIÇA DE SÃO PAULO. Disponível em http://www.tjmg.jus.br/portal/. Acesso em: 30 maio 2015.

TRIBUBAL DE JUSTIÇA DO PARANÁ. Disponível em http://www.tjpr.jus.br/. Acesso em: 30 maio 2015.

TRIBUBAL DE JUSTIÇA DE SÃO PAULO. Disponível em: http://www.tjsp.jus.br/ Acesso em: 30 maio 2015.

TRIBUNAL DE JUSTIÇA DE MINAS GERAIS. Jurisprudência. Disponível em: http://www5.tjmg.jus.br/jurisprudencia/pesquisaPalavrasEspelhoAcordao.do?\&numeroRegist ro $=3 \&$ totalLinhas $=15 \&$ paginaNumero $=3 \&$ linhasPorPagina $=1 \&$ palavras=bomparaaval $\&$ pesq uisarPor=ementa\&pesquisaTesauro=true \&orderByData $=1 \&$ pesquisaPalavras $=$ Pesquisar $\&$.

Acesso em: 20 maio 2015.

VALLE FERREIRA. Subsídios para os estudos das nulidades. Revista da Faculdade de Direito da Universidade Federal de Minas Gerais, n. 3, 1963.

VELOSO, Zeno. Nulidade do negócio jurídico. In: ALVIM, José Manoel de Arruda; CÉSAR, Joaquim Portes de Cerqueira; ROSAS, Roberto (Coord.). Aspectos Controvertidos do Novo Código Civil: escritos em homenagem ao ministro José Carlos Moreira Alves. São Paulo: Revista dos Tribunais, 2003.

VENOSA, Silvio de Salvo. Direito Civil: contratos em espécie. 4 ed. São Paulo: Atlas, 2004.

VIVANTE, Cesare. In: LUCCA, Newton de. Aspectos da Teoria Geral dos Títulos de Crédito. São Paulo: Livraria Pioneira, 1979.

VIVANTE, Cesare. In: MARTINS, Fran. Títulos de Crédito. 13 ed. v. I. Rio de Janeiro: Forense, 1998. 